\title{
Origin of Reduced Bimolecular Recombination in Blends of Conjugated Polymers and Fullerenes
}

D H K Murthy, Armantas Melianas, Zheng Tang, Gytis Juska, Kestutis Arlauskas, Fengling Zhang, Laurens D A Siebbeles, Olle Inganäs and Tom J Savenije

\section{Linköping University Post Print}

\section{Tweet}

N.B.: When citing this work, cite the original article.

Original Publication:

D H K Murthy, Armantas Melianas, Zheng Tang, Gytis Juska, Kestutis Arlauskas, Fengling Zhang, Laurens D A Siebbeles, Olle Inganäs and Tom J Savenije, Origin of Reduced Bimolecular Recombination in Blends of Conjugated Polymers and Fullerenes, 2013, Advanced Functional Materials, (23), 34, 4262-4268.

http://dx.doi.org/10.1002/adfm.201203852

Copyright: Wiley-VCH Verlag

http://www.wiley-vch.de/publish/en/

Postprint available at: Linköping University Electronic Press

http://urn.kb.se/resolve?urn=urn:nbn:se:liu:diva-102788 


\section{Origin of Reduced Bimolecular Recombination in Blends of Conjugated Polymers and Fullerenes}

By D.H.K. Murthy ${ }^{1,2}$, Armantas Melianas ${ }^{3}$, Zheng Tang $^{3}$, Gytis Juška ${ }^{4}$, Kęstutis Arlauskas $^{4}$, Fengling Zhang ${ }^{3}$, Laurens D.A. Siebbeles ${ }^{1}$, Olle Inganäs ${ }^{3}$ and Tom J. Savenije ${ }^{1 *}$

${ }^{1}$ Optoelectronic Materials Section, Department of Chemical Engineering, Delft University of Technology, 2628 BL Delft, The Netherlands

${ }^{2}$ Dutch Polymer Institute (DPI), P.O. Box 902, 5600 AX Eindhoven, The Netherlands.

${ }^{3}$ Department of Physics, Chemistry and Biology, Biomolecular and Organic Electronics, Center of Organic Electronics (COE), Linkoping University, 58183

Linkoping, Sweden

${ }^{4}$ Department of Solid State Electronics, Vilnius University, 10222 Vilnius, Lithuania 


\begin{abstract}
Bimolecular charge carrier recombination in blends of a conjugated copolymer based on a thiophene and quinoxaline (TQ1) with a fullerene derivative $\left(\mathrm{PC}_{71} \mathrm{BM}\right)$ is studied by two complementary techniques. TRMC (time resolved microwave conductance) monitors the conductance of photogenerated mobile charge carriers locally on a timescale of nanoseconds, while using photo-CELIV (charge extraction by linearly increasing voltage) charge carrier dynamics are monitored on a macroscopic scale and on tens of microseconds. Interestingly, despite these significant differences in the length and time scales, both techniques show a reduced Langevin recombination with a prefactor $\zeta$ close to 0.05 . Most importantly, we deduce that for TQ1:PC ${ }_{71} \mathrm{BM}$ blends, the $\zeta$ value is independent of temperature. The prefactor $\zeta$ can be described by the ratio between the rate constants for recombination of an electron-hole encounter complex back to the ground state, and for dissociation forming mobile charges again. On comparing TRMC data with electroluminescence measurements it can be concluded that the encounter complex and the charge transfer state have very similar energetic properties. Furthermore, the $\zeta$ value for annealed $\mathrm{P} 3 \mathrm{HT}: \mathrm{PC}_{61} \mathrm{BM}$ is approximately $10^{-4}$, while for blend systems containing an amorphous polymer $\zeta$ values are close to 1 . These large differences can be related to the extent of charge delocalization of opposite charges in an encounter complex. The enhanced delocalization for holes in well-ordered polymers is expected to reduce the binding energy between the charges, enhancing the possibility for an encounter complex to dissociate and hence smaller $\zeta$ values. This work presents basic insight into the factors governing the bimolecular recombination process, which forms a major loss mechanism limiting the efficiency of polymer solar cells.
\end{abstract}

Keywords: organic photovoltaics (OPVs); bimolecular recombination; photoCELIV; TRMC, charge transfer state; charge delocalization 


\section{Introduction}

The efficient conversion of photons into free charge carriers in blends of conjugated polymers and fullerene derivatives is quite promising for the development of bulk heterojunction (BHJ) solar cells. The power conversion efficiency (PCE) of BHJ solar cells has significantly improved from $2.5 \%$ to more than $9.5 \%$ over the last decade. ${ }^{[1]}$ This enhancement can be partly attributed to the use of low band-gap conjugated polymers to extend the spectral absorption into the NIR region and to the advance of the nanomorphology of the BHJ to improve the charge generation and transport. Further enhancement in the PCE can be achieved by minimizing geminate and bimolecular (or non-geminate) recombination of charge carriers. Particularly, bimolecular recombination is shown to strongly affect the fill factor ${ }^{[2]}$ and the $\mathrm{V}_{\mathrm{OC}}{ }^{[3]}$ that crucially influences the PCE. ${ }^{[4]}$

Charge formation in a BHJ blend starts by the absorption of a photon yielding a bound electron/hole pair or exciton. The dissociation of the exciton at the polymer fullerene interface results in a charge transfer state (CT state) in which an electron resides on the fullerene and a hole on the polymer at a limited distance. In principle, these Coulombically bound states should overcome their mutual attraction to form free charge carriers. Recently, we showed that delocalization of the charges in the CT state lowers the Coulombic binding energy between the opposite charges, assisting the separation resulting in the formation of mobile charges. ${ }^{[5]}$ In BHJ solar cells these free charges can undergo bimolecular recombination forming a major loss mechanism. Over the last years, the Langevin theory ${ }^{[6]}$ has been used to describe the recombination of charge carriers in organic semiconductors such as conjugated polymers. The Langevin recombination rate $\left(\beta_{L}\right)$ is given by Equation 1 ,

$$
L=\frac{\left.\Theta e^{+} h_{h}\right)}{0}
$$

where $e$ is the elementary charge, $\mu_{e}$ and $\mu_{h}$ are the electron and hole mobilities and $\varepsilon$, $\varepsilon_{o}$ are the relative and absolute dielectric permittivity, respectively.

For a number of BHJ blends the observed experimental bimolecular recombination rate $\left(\beta_{\text {exp }}\right)$ of charge carriers can indeed be described by Equation $1 .^{[7]}$ However, a number of polymer blends, i.e. annealed P3HT:PCBM, SiPCPDTBT:PCBM and KP115:PCBM exhibit two to four orders smaller $\beta_{\exp }$ values as compared to $\beta_{L}{ }^{[8]}$ The ratio between $\beta_{\text {exp }} / \beta_{L}$ is referred in literature as the Langevin 
prefactor, $\zeta$. Several models to explain this reduced-Langevin recombination behavior are reported: Österbacka et $a l^{[8 \mathrm{a}]}$ attributed the reduced-Langevin recombination to $2 \mathrm{D}$ recombination in the lamellar structure of conjugated polymer. Deibel et al proposed that a gradient in the carrier-concentration within a device is the reason for reducedLangevin recombination $^{[8 b]}$, while according to Szmytkowski ${ }^{[8 c]}$ it is the difference in the local dielectric constant. Furthermore, Koster et $a l^{[9]}$ proposed that bimolecular recombination is predominantly governed by the slowest charge carrier instead of the fastest one. Nevertheless, despite these research efforts, the basis for observing reduced-Langevin recombination is unclear and it is crucial to get better insight on this process to improve the PCE of organic solar cells.

In this work, we investigate the charge recombination process in blends of TQ1 with $\mathrm{PC}_{71} \mathrm{BM}$ by employing the microwave photoconductance technique (TRMC) and photogenerated charge extraction by linearly increasing voltage (photo-CELIV) techniques. The TRMC monitors the conductance of photogenerated mobile charge carriers locally (microscopic) on a timescale of nanoseconds, while the photo-CELIV monitors charge carrier dynamics on a macroscopic scale and on much longer timescales. Note that both techniques provide information on the recombination processes close to those observed under open circuit conditions. The TQ1:PC ${ }_{71} \mathrm{BM}$ ratio and the thickness of the photoactive layer are kept constant for both experiments to allow comparison of the results of both techniques. For the TRMC measurements the temperature was varied between 220 and $300 \mathrm{~K}$ and in addition, the laser intensity was varied over a factor of 30 . The TRMC traces were fitted to obtain the charge carrier mobilities and $\beta_{\exp }$ from which the prefactor $\zeta$ is deduced. Next, the recombination dynamics, and charge carrier mobilities from the photo-CELIV experiments are discussed and again the prefactor $\zeta$ is derived. Interestingly, the prefactor as determined by both techniques are found to be very close. A kinetic scheme is presented to explain the physical origin of the prefactor. 


\section{Results and Discussion}
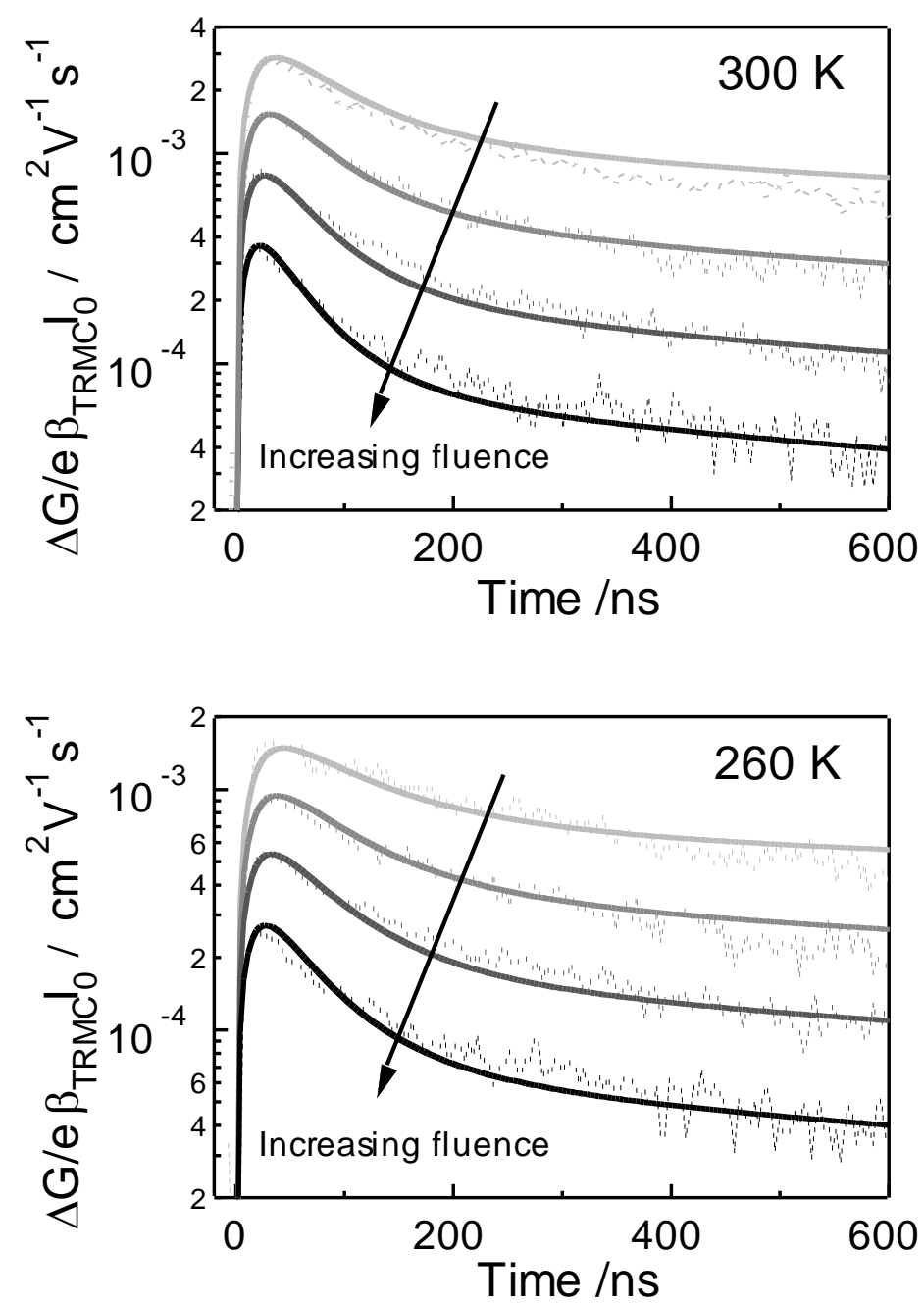

Figure 1. Photoconductance traces (dotted) normalized to the incident laser fluence for $\mathrm{TQ} 1: \mathrm{PC}_{71} \mathrm{BM}$ at indicated temperatures on varying the fluence from $1.5 \times 10^{12}$ photons.cm ${ }^{-2}$ to $5 \times 10^{13}$ photons.cm ${ }^{-2}$ using a wavelength of $612 \mathrm{~nm}$. The solid lines are fits to the data points according to the kinetic scheme 1 .

Figure 1 shows microwave photoconductance transients (dotted lines) recorded using different incident intensities varying over a factor of 30. On photoexcitation of the blend layer with a $3.5 \mathrm{~ns}$ laser pulse, the transient shows a clear rise followed by a slow decay on a time scale of hundreds of nanoseconds. Due to the $18 \mathrm{~ns}$ response time of the microwave cavity the maximum of the photoconductance signal is observed at about $30 \mathrm{~ns}$. As no electrodes are involved in TRMC measurements, the conductance decay is merely due to recombination of mobile charge recombination or trapping. ${ }^{[10]}$ 
On comparing the decay dynamics of the photoconductance traces obtained at 260 and $300 \mathrm{~K}$ shown in Figure 1, it is clear that the decay becomes faster at higher temperatures (see Figure S1 in Supporting Information). Similar observations were previously reported for $\mathrm{P} 3 \mathrm{HT}: \mathrm{PC}_{61} \mathrm{BM}$ blends. ${ }^{[11]}$ In addition, it can be noticed that the maximum change in photoconductance increases with higher temperatures. As argued for $\mathrm{P} 3 \mathrm{HT}: \mathrm{PC}_{61} \mathrm{BM}$ blends this rise can be attributed to higher electron mobility on the fullerenes, and hole mobility on the polymer, while the yield of charges was found to be temperature independent. ${ }^{[11]}$ For the present blends the activation energies are similar to those found for $\mathrm{P} 3 \mathrm{HT}: \mathrm{PC}_{61} \mathrm{BM}$ (see Supporting Information Figure S2) indicating again the yield remains constant with temperature.

To determine the bimolecular recombination rate, $\beta_{\text {exp }}$, the TRMC traces were fitted using a routine based on the photophysical model as detailed in Scheme 1. In short, photoexcitation of the blend $\left(k_{1}\right)$ is determined by the temporal profile and intensity of the laser in combination with the optical absorption of the blend at the wavelength used. Charge formation $\left(k_{2}\right)$ is assumed to be a fast (multiple) process as compared to the width of the laser pulse, with a fixed rate constant. Exciton-hole recombination $\left(k_{3}\right)$ that has been reported previously to occur in blends ${ }^{[12]}$ is a bimolecular process resulting in the decay of an excited state, however not affecting the concentration of the holes. This process has to be taken into account if light fluences are substantially higher than 1 sun, like in the TRMC experiments. Formation of a strongly bound charge transfer state, followed by geminate recombination could occur, however these intermediates do not contribute to the measured photoconductance signal. First order trapping $\left(k_{4}\right)$ and thermal release $\left(k_{5}\right)$ of charge carriers are also included, which is more pronounced at low temperatures. Apart from energetic trapping, this process $\left(k_{4}\right)$ also takes into account the diffusion of charges to more amorphous areas, which are characterized by a low mobility. Finally, the rate constant $\beta_{\text {exp }}$, represents the bimolecular recombination between mobile electrons and holes. Note that both charges $\mathrm{TQ} 1^{+}$and $\mathrm{PC}_{71} \mathrm{BM}^{-}$are expected to be mobile (see Figure S2 Supporting Information) and hence they both contribute to the photoconductance. Since the TRMC technique is not capable of discriminating between positive and negative charge carriers, in the fit routine all generated charge carriers obtain a total mobility of $\left(\mu_{e}+\mu_{h}\right)$ except for those charges that are trapped and are hence immobile. Note that TRMC experiments are performed under low 
electric filed strengths. The rate constants found might be different in solar cells operating at maximum power point. As shown in Figure 1 (solid lines) reasonable good fits are obtained for the observed traces at various incident intensities for one set of kinetic parameters using this relatively simple scheme. There is no need to assume concentration dependent bimolecular recombination rates. The supporting information contains more details regarding the fit procedure including the rate constants found at various temperatures.

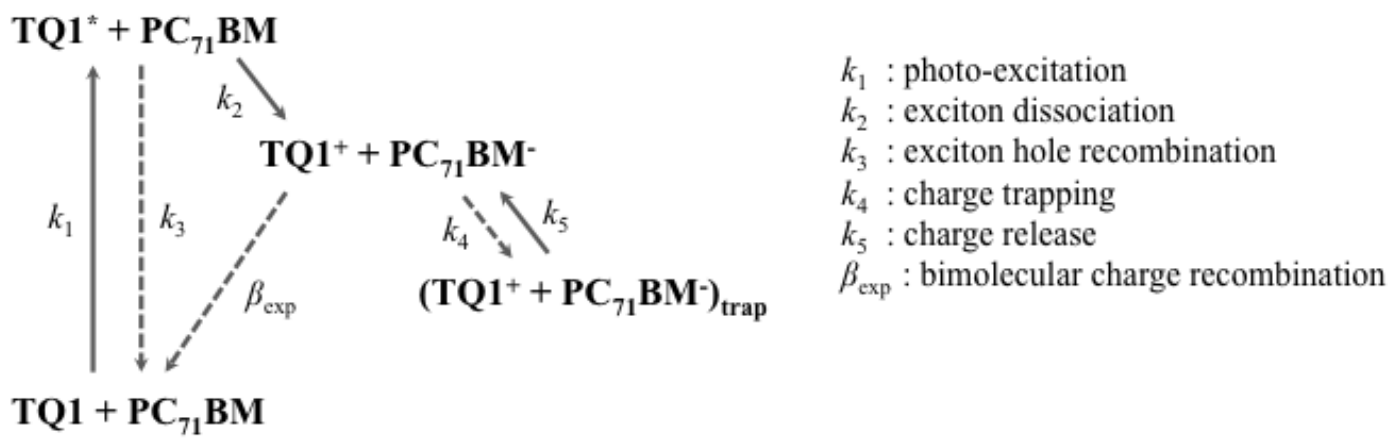

Scheme 1. Summary of the photophysical processes occurring on photoexcitation of the TQ1:PC ${ }_{71} \mathrm{BM}$ blend. $k_{3}$ is the bimolecular recombination rate constant for the decay of an excited state with a positive charge, resulting in the decay of the excited state while the concentration of holes is unaltered. The rate constant $\beta_{\exp }$ represents bimolecular (non-geminate) recombination of mobile charges.

The values of $\beta_{\text {exp }}$ determined using the above fitting method are plotted in Figure 2 versus temperature. A clear rise of the recombination rate is observed on increasing the temperature from 220 to $300 \mathrm{~K}$. Furthermore the Langevin recombination rates, $\beta_{L}$, are calculated using the total mobility of $\left(\mu_{e}+\mu_{h}\right)$ as obtained from the fitting routine and using Equation 1. These values are shown in Figure 2. The $\beta_{\exp }$ values are approximately two orders of magnitude smaller as compared to $\beta_{L}$, implying the $\beta_{\text {exp }}$ rates are reduced. The prefactor $\zeta$, determined by the ratio $\beta_{\text {exp }} / \beta_{L}$, is found to be $\approx 0.05$ and independent of the temperature from $220 \mathrm{~K}$ to $300 \mathrm{~K}$ within the experimental error. For annealed P3HT:PCBM a prefactor of $1 \times 10^{-4}$ has been determined at room temperature using a similar approach. ${ }^{[13]}$ Most importantly, the clear proportionality between $\beta_{\text {exp }}$ and $\beta_{L}$ indicates that these experimentally obtained parameters are physically related, and that the size of the prefactor $\zeta$ is related to the 
nature of the encounter complex. The physical origin of reduced bimolecular recombination is discussed later in this section.

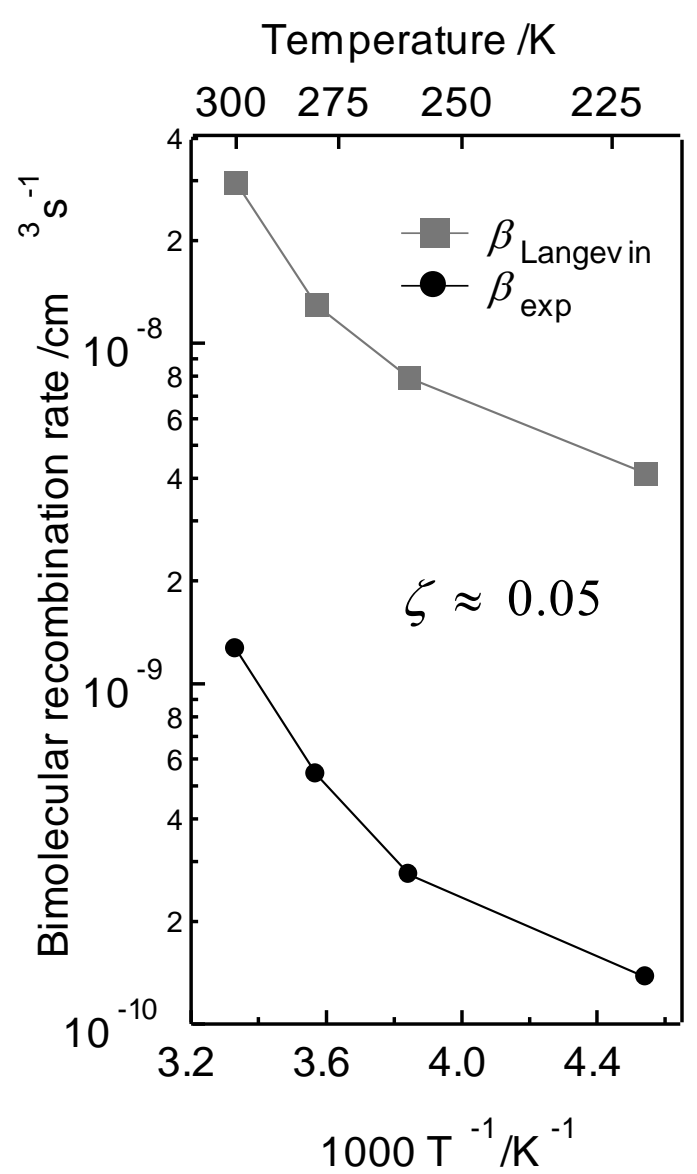

Figure 2. Effect of temperature on the bimolecular recombination rate: $\beta_{\exp }$ values are determined by fitting the decays at various temperatures and the Langevin rate $\left(\beta_{L}\right)$ is calculated according to Equation 1, using the mobility values found from the fitting routine.

Figure 3 shows the charge carrier density $n$ decay deduced by photo-CELIV experiments in the microsecond regime. Note that in this case a complete solar cell is measured, instead of $\mathrm{TQ1}: \mathrm{PC}_{71} \mathrm{BM}$ film without electrodes like in the TRMC experiment. The charge carrier mobility estimated by photo-CELIV is approximately $\mu=2 \times 10^{-4} \mathrm{~cm}^{2} \mathrm{~V}^{-1} \mathrm{~s}^{-1}$. This corresponds to $\beta_{L}$ values of $1 \times 10^{-10} \mathrm{~cm}^{3} \mathrm{~s}^{-1}$ according to Equation 1. By varying the time delay, $t_{\text {delay }}$, between the short laser pulse and the linearly increasing extraction voltage ramp, charge carrier recombination kinetics on a microsecond time scale can be examined. In Figure 3 the slope of $n$ versus $t_{\text {delay }}$ is -1 , 
which allows us to fit the data to a bimolecular decay (see Experimental). The bimolecular recombination rate, $\beta_{\text {exp }}$, is found to be $7.3 \times 10^{-12} \mathrm{~cm}^{3} \mathrm{~s}^{-1}$ (Figure 3 red), which is comparable to those reported for P3HT:PCBM based solar cells. ${ }^{[14]}$ To observe charge carrier recombination at even longer time delays (Figure 3 black color) a solar cell with a thicker active layer $d=450 \mathrm{~nm}$ was measured (see Supporting Information). The estimated bimolecular recombination rate $\beta_{\exp }=5.3 \times 10^{-}$ $12 \mathrm{~cm}^{3} \mathrm{~s}^{-1}$ and the Langevin prefactor $\zeta=0.05$ are, within experimental error, in excellent agreement in both samples. In fact, the two plots of Figure 3 can be considered as one, spanning the time range from 10 to $650 \mu \mathrm{s}$.

Most importantly the reduction factor, $\zeta$, obtained by photo-CELIV, is found to $b e \approx 0.05$ in agreement with the TRMC results discussed above. Note that, despite different measurement principles of probing charge carrier dynamics, both TRMC and photo-CELIV show reduced bimolecular recombination with similar values for $\zeta$. This issue including the substantial differences observed in charge carrier mobility using both techniques will be addressed at the end of this section.

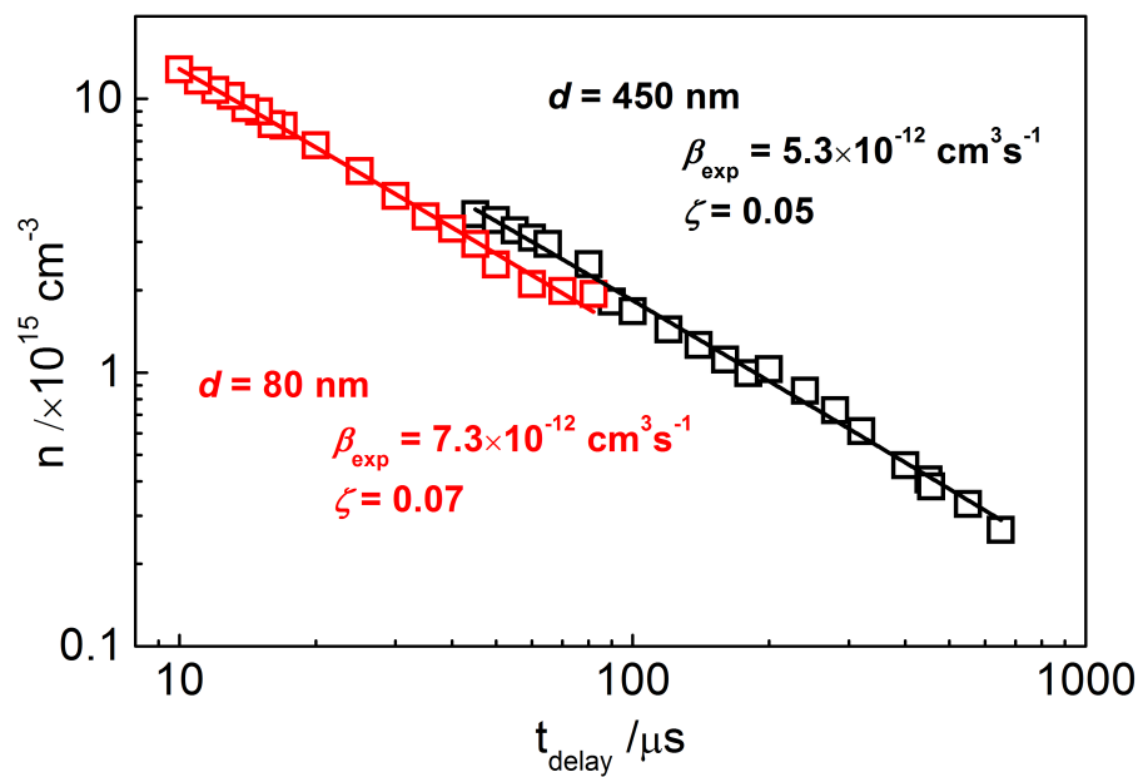

Figure 3. Extracted charge-carrier density as a function of delay time deduced by photo-CELIV at room temperature. Two solar cells of different active layer thickness, $d$, are measured (red $d=80$, black $d=450 \mathrm{~nm}$ ). Red corresponds to the same active layer as in TRMC measurements. Solid lines are fits of the data to a bimolecular decay. 


$$
\begin{aligned}
& \mathbf{T Q 1}^{+}+\mathbf{P C}_{71} \mathbf{B M}^{-} \stackrel{\beta_{\mathrm{L}}}{\stackrel{---->}{\longleftarrow}}\left(\mathrm{TQ1}^{+}+\mathbf{P C}_{71} \mathbf{B M}^{-}\right)_{\mathrm{CT}} \quad k_{\mathrm{CT}} \text { : CT generation } \\
& k_{\mathrm{CT}} \uparrow \begin{array}{ll}
k_{\mathrm{r}} & k_{\mathrm{r}}: \text { CT recombination } \\
k_{\mathrm{d}}: \text { CT dissociation }
\end{array} \\
& \mathbf{T Q 1}+\mathrm{PC}_{71} \mathbf{B M}
\end{aligned}
$$

Scheme 2. Kinetic processes involved in bimolecular recombination based on the scheme. The Langevin rate $\beta_{L}$ defines the rate for mobile opposite charge carriers to form an encounter complex. This encounter complex can decay to the ground state $\left(k_{r}\right)$ or dissociate back into mobile charges $\left(k_{d}\right)$.

In the following part, we try to understand the physical origin of the reduced bimolecular recombination. As has been reported recently and depicted in Scheme 2, the Langevin rate, $\beta_{L}$ denotes the rate for mobile charge carriers to form a so-called encounter complex. ${ }^{[13,15]}$ This complex can either undergo recombination to the ground state or dissociate back into mobile charges, depending on the rate constants $k_{r}$ and $k_{d}$. We relate the prefactor $\zeta$ to the properties of the encounter complex by assuming that $\zeta=k_{\mathrm{d}} / k_{\mathrm{r}}$. In case of reduced bimolecular recombination: $k_{\mathrm{d}}>k_{\mathrm{r}}$. For TQ1:PC ${ }_{71} \mathrm{BM}$ blends a value for $\zeta$ of $\approx 0.05$ implies that recombination to the ground state occurs only one out of approximately twenty times an encounter complex is formed. Furthermore, the $\zeta$ value for annealed P3HT: $\mathrm{PC}_{61} \mathrm{BM}$ is approximately $10^{-}$ ${ }^{4[13]}$ i.e. two orders smaller than found for TQ1:PC ${ }_{71} \mathrm{BM}$. This implies that a complex formed in a $\mathrm{P} 3 \mathrm{HT}: \mathrm{PC}_{61} \mathrm{BM}$ blend has an approximately 100 times higher chance to dissociate into free charges than a complex formed in TQ1:PC ${ }_{71} \mathrm{BM}$. To explain this large difference, the $\zeta$ values might tentatively be related to the extent of charge delocalization of opposite charges in an encounter complex. As has been suggested previously by theoretical modeling, delocalization reduces the binding energy between the charges ${ }^{[16]}$ enhancing the possibility for a complex to dissociate. On comparing the morphology of the polymer constituents in both blends, it can be concluded that the crystalline P3HT is more ordered than TQ1, which is liquid crystalline at best. ${ }^{[17]}$ The high crystallinity of P3HT might result in a more extensive charge delocalization of the positive charge carrier in the polymer domains. This results in a higher chance for the complex to dissociate, and hence a smaller $\zeta$ values for $\mathrm{P} 3 \mathrm{HT}: \mathrm{PC}_{61} \mathrm{BM}$ in comparison to TQ1:PC ${ }_{71} \mathrm{BM}$. 
To substantiate our model we collected the reported recombination rates for a number of blends by examining existing literature. The bimolecular recombination rate found in blends consisting of an amorphous polymer such as PCPDTBT, ${ }^{[15]}$ MDMO-PPV,${ }^{[18]}$ PCDTBT, ${ }^{[19]}$ regiorandom P3HT, ${ }^{[4 b, 7]}$ are close to values predicted by Langevin recombination theory i.e. $\zeta$ values are close to 1 . However, blends containing polymers, such as silicon substituted PCPDTBT, ${ }^{[8 f]}$ fluorine substituted PCPDTBT, ${ }^{[20]}$ silole based polymers $(\mathrm{KP} 115)^{[8 \mathrm{~d}]}$ and annealed $\mathrm{P} 3 \mathrm{HT}^{[21]}$ exhibited a reduced bimolecular recombination rate. Interestingly, the latter set of polymers has a common feature: improved planarity of the polymer backbone and better $\pi-\pi$ stacking leading to a well-ordered nanomorphology. ${ }^{[22]}$ The enhancement in the ordering nature of the polymer allows delocalization of the charge carriers, which positively affects the dissociation rate, $k_{\mathrm{d}}$ of the encounter complex and hence results in a reduced bimolecular recombination.

A striking question now is whether this encounter complex has similar properties as the CT state formed on optical excitation of a blend. More specifically: Is the binding energy between opposite charges in each of these complexes equal? If the complexes have similar properties the photon energy required to excite an electron from the HOMO of the TQ1 to the LUMO of $\mathrm{PC}_{71} \mathrm{BM}\left(k_{C T}\right.$ in Scheme 2) should match the energy of the luminescence corresponding to the radiative decay of an encounter complex to the ground state. The latter could be measured by electroluminescence (EL) and is found to amount to $\approx 1.4 \mathrm{eV} .{ }^{[23]}$ Hence optical excitation at this wavelength should result in the promotion of an electron from the HOMO of the polymer directly to the LUMO of the fullerene, yielding the CT state. Figure 4 shows a TRMC action spectrum where the maximum photoconductance values normalized to the incident intensity $\left(\Delta G_{\max } / I_{0}\right)$ are plotted as function of the excitation wavelength. Interestingly, when exciting at $1.41 \mathrm{eV}$, where neither TQ1 nor $\mathrm{PC}_{71} \mathrm{BM}$ absorbs, formation of mobile charge carriers is observed. From the onset in the TRMC action spectrum it is inferred that the energy of the CT state amounts to $\approx 1.41 \mathrm{eV}$. In addition, the energy of the CT state deduced from the Fourier-transform photocurrent spectroscopy (FTPS) technique was found to be $\approx 1.45 \mathrm{eV}$. ${ }^{[24]}$ From these observations it can be concluded that the energetic properties of the encounter complex and the $\mathrm{CT}$ state for TQ1:PC ${ }_{71} \mathrm{BM}$ are identical. For annealed blends of P3HT:PC ${ }_{61} \mathrm{BM}$ the energies found using EL and TRMC match perfectly, again 
indicating that the encounter complex is similar in nature as the CT state. ${ }^{[25]}$ These observations suggest that bimolecular recombination occurs via an intermediate resembling the CT state.

\section{Energy /eV}

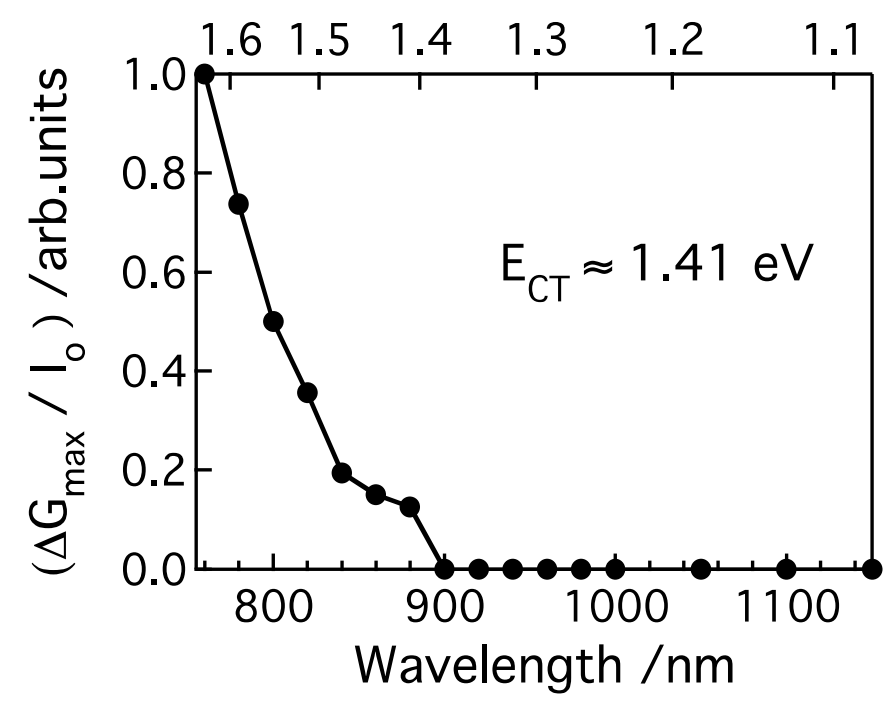

Figure 4: Intensity normalized photoconductance action spectrum for a blend of TQ1 with $\mathrm{PC}_{71} \mathrm{BM}$.

Finally we address the question why both techniques giving such different values for the charge carrier mobility, however still yield comparable $\zeta$ values. As mentioned above, both techniques probe at different times and length scales. [26] Identical to recent $\mathrm{THz}$ measurements on $\mathrm{TQ1}: \mathrm{PCBM}^{[27]}$, using TRMC the highly mobile charges are predominantly probed. These mobile charges rapidly face a counter charge to form an encounter complex. Thus if $\left(\mu_{e}+\mu_{h}\right)$ is high, also the bimolecular recombination rate, $\beta_{\text {exp }}$, is high. With photo-CELIV, apart from mobile charges, also charges that have (for some period) been immobilized due to trapping are measured. This implies that the observed mean mobility of the carriers is substantially lower than measured with TRMC. However, as parts of these charges have been immobilized, ${ }^{[26]}$ bimolecular recombination is reduced accordingly. Despite the differences in the measured $\left(\mu_{e}+\mu_{h}\right)$ and $\beta_{\text {exp }}$, the observed $\zeta$ values obtained by both photo-CELIV and TRMC are equal as $\zeta$ depends mostly on the nature of the encounter complex. Also, from above considerations we can deduce that for a specific blend the $\zeta$ value is independent of the mobility. This conclusion is supported by our temperature dependent TRMC measurements: By changing the 
temperature the mobility is in fact varied, however the $\zeta$ is constant. (See Figure 2) In view of kinetic Scheme 2 a constant $\zeta$ value means that the ratio between $k_{r}$ and $k_{d}$ remains constant, which implies that either both rate constants stay the same or both rate constants are in the same way dependent on the mobility of the charge carriers. As it is not directly evident how $k_{r}$ should be affected by the mobility we suggest that both $k_{r}$ and $k_{d}$ are independent of the mobility. This is also in line with our previous arguments that $k_{d}$ is predominantly affected by charge delocalization.

\section{Conclusions}

We have investigated the charge carrier recombination processes in TQ1:PC ${ }_{71} \mathrm{BM}$ blends by using the TRMC and photo-CELIV techniques. TRMC monitors the conductance of photogenerated mobile charge carriers locally while using photo-CELIV charge carrier dynamics are monitored on a macroscopic scale. Despite the significant differences in the spatial and temporal scales involved in both techniques, a reduced bimolecular recombination with a prefactor, $\zeta$, close to 0.05 is observed. Temperature dependent TRMC measurements indicate a clear proportionality between experimentally measured $\beta_{L}$ and $\beta_{\text {exp }}$, suggesting that the size of the prefactor $\zeta$ is related to the nature of the encounter complex. The prefactor $\zeta$ can be described by the ratio between the rate constants for recombination of the encounter complex back to the ground state $\left(k_{\mathrm{r}}\right)$ and for dissociation forming mobile charges again $\left(k_{d}\right)$. From the TRMC action spectra and electroluminescence measurements it can be concluded that both the encounter complex and the CT state have identical energetic properties for TQ1:PC ${ }_{71} \mathrm{BM}$ blends, which is also true for $\mathrm{P} 3 \mathrm{HT}: \mathrm{PC}_{61} \mathrm{BM}$ blends. These observations suggest that bimolecular recombination occurs via an intermediate resembling the CT state.

For blend systems, containing an amorphous polymer $\zeta$ values close to 1 have been observed. The $\zeta$ value for annealed $\mathrm{P} 3 \mathrm{HT}: \mathrm{PC}_{61} \mathrm{BM}$ is much smaller, approximately $10^{-4[13]}$ i.e. two orders smaller than found for TQ1:PC ${ }_{71} \mathrm{BM}$. These large differences between the $\zeta$ values can be related to the extent of charge delocalization of opposite charges in an encounter complex. The enhancement in the ordering nature of the polymer allows delocalization of the charge carriers, which is expected to reduce the binding energy between them, enhancing the dissociation rate $k_{\mathrm{d}}$ of the encounter complex. The higher possibility for a complex to dissociate leads 
to smaller $\zeta$ values. Thus, inducing the ordering of the conjugated polymer in addition to fullerene segregation seems like a prerequisite to achieve reduced bimolecular recombination.

\section{Experimental}

In this work, blend of a low band gap conjugated polymer based on thiophene and quinoxaline named as poly[2,3-bis-(3-octyloxyphenyl)quinoxaline-5,8-diyl- alt thiophene-2,5-diyl] (TQ1) with a fullerene derivative, $\mathrm{PC}_{71} \mathrm{BM}$ is used. The blend solution of TQ1 with $\mathrm{PC}_{71} \mathrm{BM}$ (1:2.5 weight ratio) is prepared using orthodichlorobenzene solvent. The thickness of the photoactive layer is $\sim 80 \mathrm{~nm}$. This blend composition has previously demonstrated 6\% PCE with a remarkably high $0.9 \mathrm{~V}$ open circuit voltage. Reports on the synthesis of the TQ1, optical, morphological and electrical properties of TQ1:PC ${ }_{71} \mathrm{BM}$ blend is detailed by Wang et $\mathrm{al}[28]$.

\section{TRMC.}

The time-resolved microwave conductivity (TRMC) technique is employed to investigate the formation of mobile charge carriers and their decay with time. In using this technique, the change in conductance of the film, on photoexcitation is recorded on a nanosecond time scale without applying external electrodes. Temperature dependent TRMC measurements were carried out using a custom-made liquid nitrogen cooled microwave cavity with a resonance frequency at ca $8.45 \mathrm{GHz}$. Samples were photoexcited with a 3 ns laser pulse from an optical parametric oscillator pumped at $355 \mathrm{~nm}$ with the third harmonic of a Q-switched Nd:YAG laser (Vibrant II, Opotek). Photogeneration of mobile charge carriers in the sample leads to an increase of the conductance, $\Delta G(t)$, and consequently to an enhanced absorption of microwave power by the sample. The time-dependent change of the conductance is obtained from the normalized change in microwave power $(\Delta P(t) / P)$ reflected from the cavity according to

$$
\frac{\Delta P(t)}{P}=-K \Delta G(t)
$$

The geometrical dimensions of the cavity and dielectric properties of the media in the microwave cavity determine the sensitivity factor, $K$. From the maximum change in the conductance $\left(\Delta G_{\max }\right)$ and the incident light $\left(I_{0}\right)$, the parameter $\eta \Sigma \mu$ denoting the 
product of the charge carrier generation yield $(\eta)$ per absorbed photon and the sum of the electron and hole mobilities $(\Sigma \mu)$ can be calculated using

$$
\eta \Sigma \mu=\frac{\Delta G_{\max }}{I_{0} \beta_{T R M C} e}
$$

where $\beta_{\text {TRMC }}$ is the ratio between the broad and narrow inner dimensions of the waveguide and $e$ is the elementary charge. For more experimental details see references [29].

\section{Photo-CELIV.}

Photogenerated charge carrier extraction by linearly increasing voltage (photo-CELIV) technique is employed to study charge carrier transport and recombination on a $\mu$ s time scale. Charge carriers are generated by a 3 ns laser pulse from an optical parametric oscillator (GWU VersaScan/120MB) pumped at $355 \mathrm{~nm}$ with the third harmonic of a Q-switched Nd:YAG laser (New Wave Research, Tempest 10). Excitation wavelength was $500 \mathrm{~nm}$. After a time delay, $t_{\text {delay }}$, photogenerated charge carriers are extracted by a linearly increasing voltage, applied by a digital function generator (Stanford Research DS 345). The solar cell is kept at a constant offset voltage (close to $\mathrm{V}_{\mathrm{OC}}$ ) prior to extraction to avoid photogenerated charge carrier leakage out of the device. However, applied constant offset voltage, $U_{\text {off, }}$ could lead to charge carrier injection to the active layer from the electrodes, which might affect the experimental results. Thus, $U_{\text {off }}$ was chosen so that both the photogenerated charge carrier leakage and the injection current would be minimal (See supporting information for further discussion). Transients were recorded by a digital storage oscilloscope (Tektronix TDS 220).

Semitransparent solar cells in inverted geometry with the following structure: ITO/PFPA-1/TQ1:PC 71 BM/PEDOT:PSS PH1000 were measured (See Figure S4 of the Supporting Information for device characteristics). Active layer fabrication was identical to that used for TRMC sample preparation, leading to the same active layer thickness, morphology etc. For more details on sample fabrication, device parameters etc. see reference [30].

Charge carrier mobility is estimated from the temporal position of the extraction current maximum, $t_{\max }$, which largely depends on the experimental conditions[31]. The formula used for the calculations is dependent on the 
approximation method employed. In this work charge carrier mobility is estimated as suggested by Juška et al [32]:

$\mu=\frac{2}{3} \frac{d^{2}}{A t_{\max }^{2}} \frac{1}{1+0.36 \frac{\Delta j}{j_{0}}}$

where $A$ is the voltage ramp speed, $d$-sample thickness, $\Delta j$ - maximum extraction current, $j_{0}$ - initial current. For more detailed information see references [31-32].

Charge carrier recombination is studied by varying the time delay between the short laser pulse and the linearly increasing voltage. Firstly, a CELIV transient in the dark is measured as a reference. Photo-CELIV transients at different time delays are then recorded. By subtracting the reference CELIV transient from the photo-CELIV transients and integrating the resulting data, extracted charge as a function of time delay is obtained. Charge carrier concentration, $n$, is obtained by dividing the extracted charge by the volume of the active layer. The resulting plots of $n$ versus $t_{\text {delay }}$ are fitted to a power law in a log-log plot. The differential equation for bimolecular recombination:

$$
\frac{d n}{d t}=\quad \exp ^{2}
$$

has the general solution (assuming concentration independent $\beta_{\text {exp }}$ ):

$$
n(t)=\frac{1}{\exp t+1 / n(0)}
$$

which has a slope of -1 in a log-log plot. We find our power law fits to also have a slope of -1 . Hence we can fit our data points according to (5). Obtained charge carrier mobility and bimolecular recombination values are then used to calculate the Langevin prefactor, $\zeta$.

\section{Acknowledgement}

The work of DHKM forms the research program of the Dutch Polymer Institute (DPI, project \#681). Research on organic photovoltaics at Linköping University is financed by the Swedish Energy Agency. Research at Vilnius University was funded by the European Social Fund under the Global Grant measure. We gratefully acknowledge the synthesis of polymers from Dr. Ergang Wang and Prof. 
Mats Andersson, Chalmers University of Technology, and discussions with L.Mattias Andersson, Lund University.

\section{Supporting Information}

Supporting Information is available online from Wiley InterScience or from the author.

\section{References}

[1] a) L. T. Dou, J. B. You, J. Yang, C. C. Chen, Y. J. He, S. Murase, T. Moriarty, K. Emery, G. Li, Y. Yang, Nature Photon. 2012, 6, 180-185; b) M. A. Green, K. Emery, Y. Hishikawa, W. Warta, E. D. Dunlop, Prog. Photovolt: Res. Appl. 2012, 20, 12-20; c) R. F. Service, Science 2011, 332, 293-293.

[2] R. Mauer, I. A. Howard, F. Laquai, J. Phys. Chem. Lett. 2010, 1, 3500-3505.

[3] D. Credgington, R. Hamilton, P. Atienzar, J. Nelson, J. R. Durrant, $A d v$. Funct. Mater. 2011, 21, 2744-2753.

[4] a) A. Pivrikas, H. Neugebauer, N. S. Sariciftci, IEEE J. Sel. Top. Quantum Electron. 2010, 16, 1746-1758; b) A. Pivrikas, N. S. Sariciftci, G. Juska, R. Osterbacka, Prog. Photovolt: Res. Appl. 2007, 15, 677-696; c) P. E. Keivanidis, V. Kamm, W. M. Zhang, G. Floudas, F. Laquai, I. McCulloch, D. D. C. Bradley, J. Nelson, Adv. Funct. Mater. 2012, 22, 2318-2326.

[5] D. H. K. Murthy, M. Gao, M. J. W. Vermeulen, L. D. A. Siebbeles, T. J. Savenije, J. Phys. Chem. C 2012, 116, 9214-9220.

[6] P. Langevin, Ann. Chim. Phys. 1903, 28, 433-530.

[7] A. Pivrikas, R. Osterbacka, G. Juska, K. Arlauskas, H. Stubb, Synt. Met. 2005, $155,242-245$.

[8] a) R. Osterbacka, A. Pivrikas, G. Juska, A. Poskus, H. Aarnio, G. Sliauzys, K. Genevicius, K. Arlauskas, N. S. Sariciftci, IEEE J. Sel. Top. Quantum Electron. 2010, 16, 1738-1745; b) C. Deibel, A. Wagenpfahl, V. Dyakonov, Phys. Rev. B 2009, 80, 075203; c) J. Szmytkowski, Chem. Phys. Lett. 2009, 470, 123-125; d) T. M. Clarke, J. Peet, P. Denk, G. Dennler, C. Lungenschmied, A. J. Mozer, Energy Environ. Sci. 2012, 5, 5241-5245; e) A. Pivrikas, G. Juska, A. J. Mozer, M. Scharber, K. Arlauskas, N. S. Sariciftci, H. Stubb, R. Osterbacka, Phys. Rev. Lett. 2005, 94, 176806; f) M. C. Scharber, M. Koppe, J. Gao, F. Cordella, M. A. Loi, P. Denk, M. Morana, H. J. Egelhaaf, K. Forberich, G. Dennler, R. Gaudiana, D. Waller, Z. G. Zhu, X. B. Shi, C. 
J. Brabec, Adv. Mater. 2010, 22, 367-370; g) T. M. Clarke, D. B. Rodovsky, A. A. Herzing, J. Peet, G. Dennler, D. DeLongchamp, C. Lungenschmied, A. J. Mozer, $A d v$. Energy Mater. 2011, 1, 1062-1067.

[9] L. J. A. Koster, V. D. Mihailetchi, P. W. M. Blom, Appl. Phys. Lett. 2006, 88, 052104.

[10] T. J. Savenije, D. H. K. Murthy, M. Gunz, J. Gorenflot, L. D. A. Siebbeles, V. Dyakonov, C. Deibel, J. Phys. Chem. Lett. 2011, 2, 1368-1371.

[11] W. J. Grzegorczyk, T. J. Savenije, T. E. Dykstra, J. Piris, J. M. Schins, L. D. A. Siebbeles, J. Phys. Chem. C 2010, 114, 5182-5186.

[12] a) J. M. Hodgkiss, S. Albert-Seifried, A. Rao, A. J. Barker, A. R. Campbell, R. A. Marsh, R. H. Friend, Adv. Funct. Mater. 2012, 22, 1567-1577; b) A. J. Ferguson, N. Kopidakis, S. E. Shaheen, G. Rumbles, J. Phys. Chem. C 2008, 112, 9865-9871.

[13] A. J. Ferguson, N. Kopidakis, S. E. Shaheen, G. Rumbles, J. Phys. Chem. C 2011, 115, 23134-23148.

[14] G. Juska, G. Sliauzys, K. Genevicius, K. Arlauskas, A. Pivrikas, M. Scharber, G. Dennler, N. S. Sariciftci, R. Osterbacka, Phys. Rev. B 2006, 74, 115314.

[15] S. Yamamoto, H. Ohkita, H. Benten, S. Ito, J. Phys. Chem. C 2012, 116, 14804-14810.

[16] C. Deibel, T. Strobel, V. Dyakonov, Phys. Rev. Lett. 2009, 103, 036402.

[17] E. Wang, J. Bergqvist, K. Vandewal, Z. Ma, L. Hou, A. Lundin, S. Himmelberger, A. Salleo, C. Müller, O. Inganäs, F. Zhang, M. R. Andersson, Conformational Disorder Enhances Solubility and Photovoltaic Performance of a Thiophene-Quinoxaline Copolymer, 2012, Submitted.

[18] G. Dennler, A. J. Mozer, G. Juska, A. Pivrikas, R. Osterbacka, A. Fuchsbauer, N. S. Sariciftci, Org. Electron. 2006, 7, 229-234.

[19] T. M. Clarke, J. Peet, A. Nattestad, N. Drolet, G. Dennler, C. Lungenschmied, M. Leclerc, A. J. Mozer, Org. Electron. 2012, 13, 2639-2646.

[20] S. Albrecht, S. Janietz, W. Schindler, J. Frisch, J. Kurpiers, J. Kniepert, S. Inal, P. Pingel, K. Fostiropoulos, N. Koch, D. Neher, J. Am. Chem. Soc. 2012, 134, 14932-14944.

[21] C. Deibel, A. Baumann, V. Dyakonov, Appl. Phys. Lett. 2008, 93.

[22] a) S. Subramaniyan, H. Xin, F. S. Kim, S. Shoaee, J. R. Durrant, S. A. Jenekhe, Adv. Energy Mater. 2011, 1, 854-860; b) H. J. Son, W. Wang, T. Xu, Y. Y. Liang, Y. E. Wu, G. Li, L. P. Yu, J. Am. Chem. Soc. 2011, 133, 1885-1894; c) P. 
Vanlaeke, A. Swinnen, I. Haeldermans, G. Vanhoyland, T. Aernouts, D. Cheyns, C. Deibel, J. D'Haen, P. Heremans, J. Poortmans, J. V. Manca, Sol. Energy Mater. Sol. Cells 2006, 90, 2150-2158.

[23] Z. Tang, L. M. Andersson, Z. George, K. Vandewal, K. Tvingstedt, P. Heriksson, R. Kroon, M. R. Andersson, O. Inganas, Adv. Mater. 2012, 24, 554-558.

[24] K. Vandewal, K. Tvingstedt, O. Inganas, Phys. Rev. B 2012, 86, 035212.

[25] K. Tvingstedt, K. Vandewal, A. Gadisa, F. L. Zhang, J. Manca, O. Inganas, J. Am. Chem. Soc. 2009, 131, 11819-11824.

[26] A. Baumann, T. J. Savenije, D. H. K. Murthy, M. Heeney, V. Dyakonov, C. Deibel, Adv. Funct. Mater. 2011, 21, 1687-1692.

[27] C. S. Ponseca, A. Yartsev, E. Wang, M. R. Andersson, D. Vithanage, V. Sundstrom, J. Am. Chem. Soc. 2012, 134, 11836-11839.

[28] E. G. Wang, L. T. Hou, Z. Q. Wang, S. Hellstrom, F. L. Zhang, O. Inganas, M. R. Andersson, Adv. Mater. 2010, 22, 5240-5244.

[29] a) J. E. Kroeze, T. J. Savenije, M. J. W. Vermeulen, J. M. Warman, J. Phys. Chem. B 2003, 107, 7696-7705; b) A. Huijser, T. J. Savenije, J. E. Kroeze, L. D. A. Siebbeles, J. Phys. Chem. B 2005, 109, 20166-20173.

[30] Z. Tang, Z. George, Z. Ma, J. Bergqvist, K. Tvingstedt, K. Vandewal, E. Wang, L. M. Andersson, M. R. Andersson, F. Zhang, O. Inganäs, Adv. Energy Mater. 2012, 2, 1467-1476.

[31] G. Juska, K. Arlauskas, M. Viliunas, K. Genevicius, R. Osterbacka, H. Stubb, Phys. Rev. B 2000, 62, R16235-R16238.

[32] N. Nekrašas, K. Genevicius, M. Viliunas, G. Juška, Chemical Physics 2012, $404,56-59$. 


\title{
Origin of Reduced Bimolecular Recombination in Blends of Conjugated Polymers and Fullerenes
}

\author{
By D.H.K. Murthy ${ }^{1,2}$, Armantas Melianas ${ }^{3}$, Zheng Tang ${ }^{3}$, Gytis Juška ${ }^{4}$, Kęstutis \\ Arlauskas $^{4}$, Fengling Zhang ${ }^{3}$, Laurens D.A. Siebbeles ${ }^{1}$, Olle Inganäs ${ }^{3}$ and Tom J. \\ Savenije ${ }^{1^{*}}$ \\ ${ }^{1}$ Optoelectronic Materials Section, Department of Chemical Engineering, Delft \\ University of Technology, 2628 BL Delft, The Netherlands \\ ${ }^{2}$ Dutch Polymer Institute (DPI), P.O. Box 902, 5600 AX Eindhoven, The Netherlands. \\ ${ }^{3}$ Department of Physics, Chemistry and Biology, Biomolecular and Organic \\ Electronics, Center of Organic Electronics (COE), Linköping University, 58183 \\ Linköping, Sweden \\ ${ }^{4}$ Department of Solid State Electronics, Vilnius University, 10222 Vilnius, Lithuania
}

\section{Supporting Information}

\section{Fitting of TRMC transients}

To determine the bimolecular recombination rate between mobile electrons and holes, $\beta_{\text {exp }}$, the TRMC traces were fitted using a routine based on the photophysical model as detailed in Scheme 1. Photo excitation of the blend is determined by the actual temporal profile and intensity of the laser in combination with the optical attenuation of the blend at the used wavelength and described by generation term $g(\mathrm{t})$. For the calculations the concentrations within the blend film are assumed to be homogeneous. Charge formation $\left(k_{2}\right)$ is assumed to be a fast (multiple) first order process including exciton formation, exciton diffusion and exciton dissociation with a fixed rate constant of $1 \times 10^{9} \mathrm{~s}^{-1}$. Although we realize that this value might be too slow, it does not affect the fitting procedure. Bimolecular excitonhole recombination $\left(k_{3}\right)$ process results in the decay of an excited state, however not affecting the concentration of the holes. Trapping $\left(k_{4}\right)$ and thermal release $\left(k_{5}\right)$ of charge carriers are also included. Apart from energetic trapping, this process $\left(k_{4}\right)$ also takes into account the diffusion of charges to more amorphous areas, which are characterized by a low mobility. Concentrations are calculated by numerically solving 
a set of differential equations as given below using Igor Pro. For simplicity the fullerene concentrations are not taken into account in the differential equations. Essential is that all traces using different intensities are described with one set of rate constants for each temperature.

$$
\begin{aligned}
& \frac{[T Q 1]}{t}=g(t)+k_{3}\left[T Q 1^{*}\right]\left[T Q 1^{+}\right]+\left[T Q 1^{+}\right]^{2} \\
& \frac{\left[T Q 1^{*}\right]}{t}=g(t) \quad k_{2}\left[T Q 1^{*}\right] \quad k_{3}\left[T Q 1^{*}\right]\left[T Q 1^{+}\right] \\
& \frac{\left[T Q 1^{+}\right]}{t}=k_{2}\left[T Q 1^{*}\right] \quad\left[T Q 1^{+}\right]^{2} \quad k_{4}\left[T Q 1^{+}\right]+k_{5}\left[T Q 1_{\text {trap }}^{+}\right] \\
& \frac{\left[T Q 1_{\text {trap }}^{+}\right]}{t}=k_{4}\left[T Q 1^{+}\right] \quad k_{5}\left[T Q 1_{\text {trap }}^{+}\right]
\end{aligned}
$$

Solving the numerical equations yields the time dependent concentration of TQ1 ${ }^{+}$ $+\mathrm{PC}_{71} \mathrm{BM}^{-}$. Next a convolution is applied with a time constant of $18 \mathrm{~ns}$ to take into account the instrumental response function of the set-up. Finally all charge carrier pairs $\left(\mathrm{TQ} 1^{+}+\mathrm{PC}_{71} \mathrm{BM}^{-}\right)$are multiplied with the summation of total mobility of $\left(\mu_{e}+\right.$ $\left.\mu_{h}\right)$. From Table 1 the thermal release rate increases with temperature, which is in agreement with enhancement of charge carrier mobility.

Table 1. Collections of parameters to fit TRMC traces

\begin{tabular}{|l|c|c|c|c|}
\hline Temperature $(\mathbf{K})$ & $\mathbf{2 2 0}$ & $\mathbf{2 6 0}$ & $\mathbf{2 8 0}$ & $\mathbf{3 0 0}$ \\
\hline $\begin{array}{l}\text { Exciton-hole } \\
\text { recombination, } k_{3}\left(\mathrm{~cm}^{3} \mathrm{~s}^{-1}\right)\end{array}$ & $0.37 \times 10^{-7}$ & $0.85 \times 10^{-7}$ & $1.46 \times 10^{-7}$ & $4.48 \times 10^{-7}$ \\
\hline Trapping, $k_{4}\left(\mathrm{~s}^{-1}\right)$ & $4.5 \times 10^{6}$ & $4.6 \times 10^{6}$ & $4.8 \times 10^{6}$ & $5 \times 10^{6}$ \\
\hline Thermal release, $k_{5}\left(\mathrm{~s}^{-1}\right)$ & $4.1 \times 10^{6}$ & $4.3 \times 10^{6}$ & $4.6 \times 10^{6}$ & $4.87 \times 10^{6}$ \\
\hline $\begin{array}{l}\text { Bimolecular } \\
\text { recombination, } \beta_{\exp }\left(\mathrm{cm}^{3} \mathrm{~s}^{-1}\right)\end{array}$ & $0.13 \times 10^{-9}$ & $0.27 \times 10^{-9}$ & $0.54 \times 10^{-9}$ & $1.26 \times 10^{-9}$ \\
\hline $\begin{array}{l}\text { Mobilities, } \mu_{e}+\mu_{h} \\
\left(\mathrm{~cm}^{2} \mathrm{~V}^{-1} \mathrm{~s}^{-1}\right)\end{array}$ & 0.008 & 0.015 & 0.025 & 0.057 \\
\hline
\end{tabular}




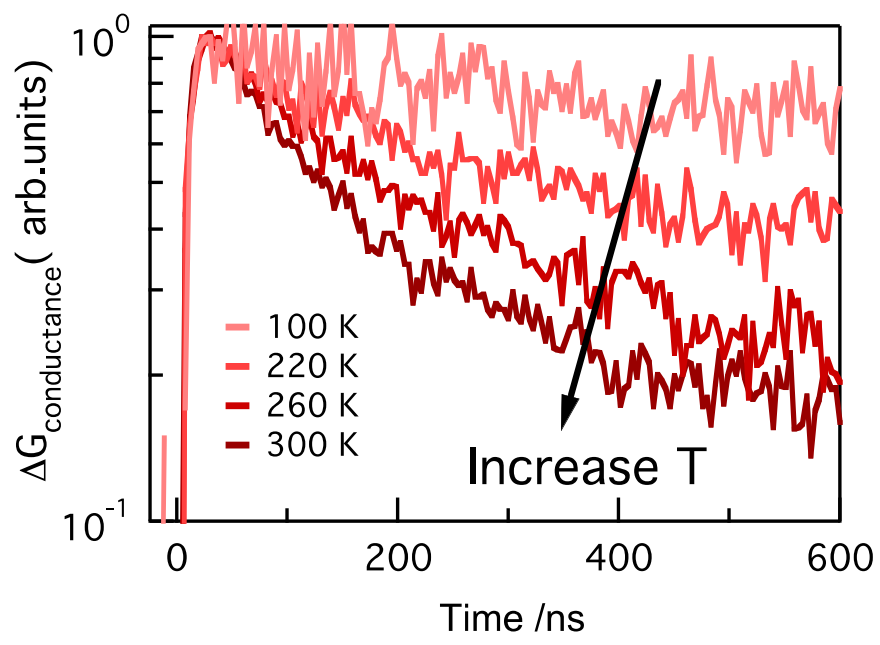

Figure S1. Normalized photoconductance transients recorded at various temperatures presented in a semi log plot obtained using a fluence of $2.2 \times 10^{13}$ photons.cm ${ }^{-2}$. With increase in temperature, the decay of the photoconductance trace becomes faster. This conclusion is in agreement with Figure 2 shown in the main text. 


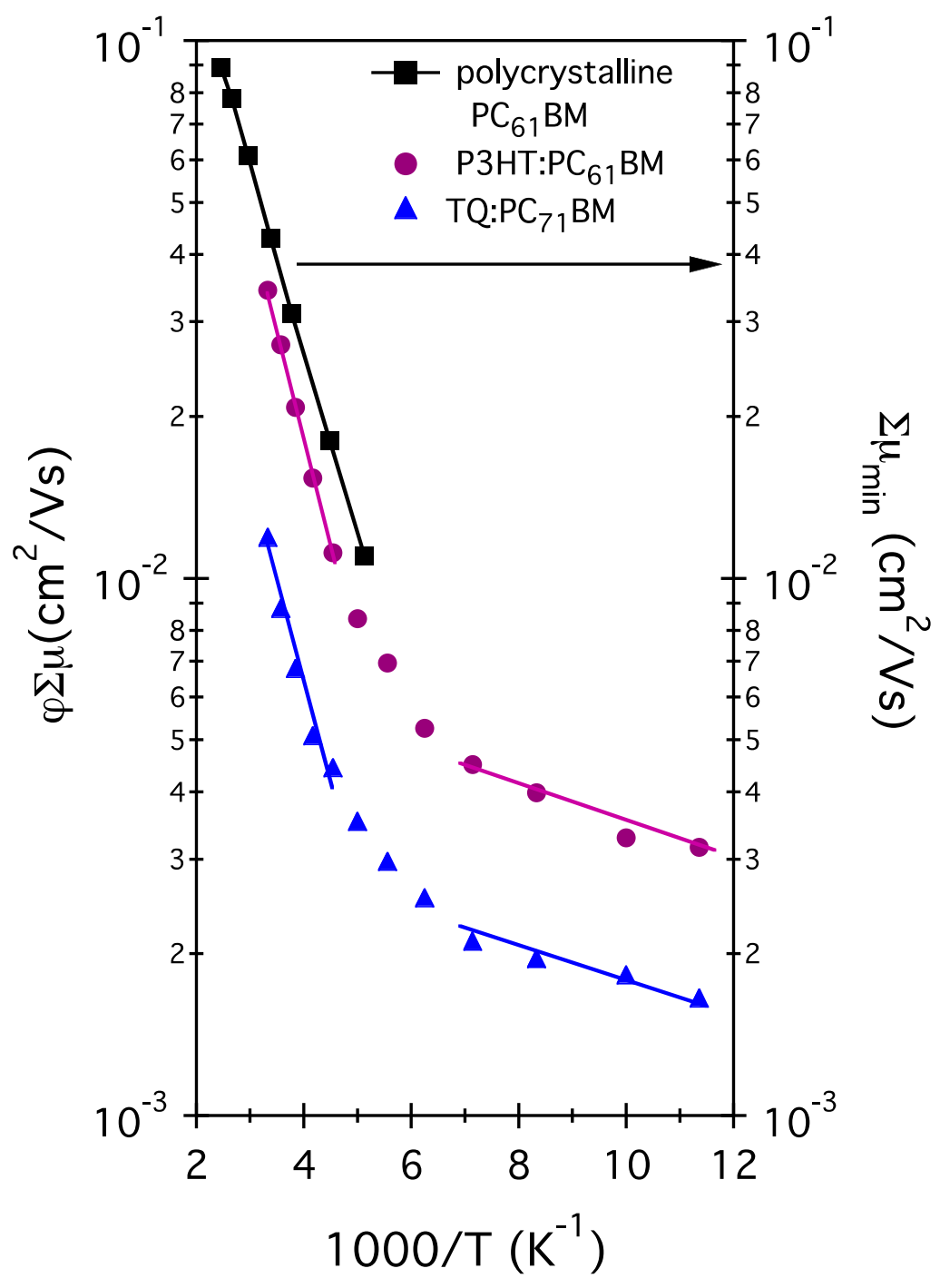

Figure S2. Yield of charges per absorbed photon $(\varphi)$ times the mobility of electron and holes $\left(\mu_{e}+\mu_{h}\right)$ values versus reciprocal temperature for TQ1:PC $71 \mathrm{BM}$ and P3HT:PCBM blends. The straight lines are results from fits of the thermal activation energy, $E_{\mathrm{a}}$, using the Arrhenius behavior $\varphi \Sigma\left(\mu_{e}+\mu_{h}\right) \approx \exp \left(-E_{\mathrm{a}} / k_{\mathrm{B}} T\right)$. For these blends, two distinct $E_{a}$ values were determined: $70 \mathrm{meV}$ above $220 \mathrm{~K}$ and $7 \pm 3 \mathrm{meV}$ below $120 \mathrm{~K}$ that are comparable to annealed P3HT:PCBM ${ }^{[1],[2]}$ blends spin coated from dichlorobenzene solvent. These $E_{a}$ values are attributed to thermally activated charge transport of electrons in fullerene domains at $\mathrm{T}>220 \mathrm{~K}^{[3]}$ and to holes in TQ1 at $\mathrm{T} \leq 150 \mathrm{~K}$. From these temperature dependent experiments, it is clear that electrons in the PCBM are contributing most to the conductance at room temperature at used frequencies. 


\section{Photo-CELIV}

The solar cell is kept at a constant offset voltage (close to $\mathrm{V}_{\mathrm{OC}}$ ) prior to extraction. This however does not guarantee that all of the photogenerated charge carriers stay in the active layer. Some of the carriers leak out of the device before the extraction starts. Such leakage might affect a proper quantification of the bimolecular recombination rate. To minimize leakage losses prior to extraction a solar cell with a $450 \mathrm{~nm}$ active layer was measured. From Figure 3 it is reasonable to assume that the influence of leakage on the estimated $\beta_{\text {exp }}$ can be ignored because they are in excellent agreement in both cases. Most importantly, by minimizing leakage losses it was possible to extend the charge carrier extraction experiment to much longer time delays, $t_{\text {delay }}$ (Figure 3 black).

Additionally, according to the methodology outlined by Juška et al the Langevin prefactor can also be estimated by an intensity dependent study of the $\Delta j / j_{0}$ ratio, ${ }^{[4]}$ where $\Delta j$ is the maximum extraction current, $j_{0}$-initial current. With increasing light intensity $\Delta j / j_{0}$ saturates at $\Delta j / j_{0}=1 / \zeta{ }^{[4]}$ In case of a solar cell with a $450 \mathrm{~nm}$ active layer (less leakage losses), $\Delta j / j_{0}$ saturation with light intensity at $\Delta j>j_{0}$ was observed (similarly as in Figure S3), which indicates reduced Langevin recombination. ${ }^{[4]}$ However, due to leakage, discussed above, this would have led to an underestimate of the Langevin prefactor. For the methodology employed in the main text, however, leakage can be ignored.

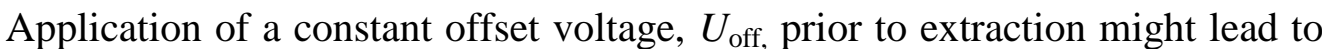
injection of charge carriers from the electrodes into the active layer. Such injected carriers could increase the experimentally observed bimolecular recombination rate, $\beta_{\text {exp }}$, leading to an overestimate of $\beta_{\text {exp }}$. Even though $U_{\text {off, }}$ was chosen to minimize the injection current, care has to be taken. To illustrate this issue Figure $\mathbf{S 3}$ shows the photo-CELIV transients for a solar cell with a $450 \mathrm{~nm}$ active layer. The difference in the dark CELIV transients with and without the applied offset voltage represents the amount of injected charge carriers. As is immediately apparent from Figure S3 the photo-CELIV peaks are substantial larger than the injection peak, especially for short time delays. Thus, injection does not influence the experiment, at least for short $t_{\text {delay }}$. For longer time delays it might. However, the experiment data for the device with the $80 \mathrm{~nm}$ thin active layer presented in Figure 3 is at longer time delays $(40-80 \mu \mathrm{s}$ for that experiment) in excellent agreement with the thick active layer data. Thus, it is 
reasonable to assume that injected charge carriers are not affecting the measurement. Moreover, the slope of -1 in Figure 3 is already sufficient to state that the experiment is not influenced by charge carrier injection.

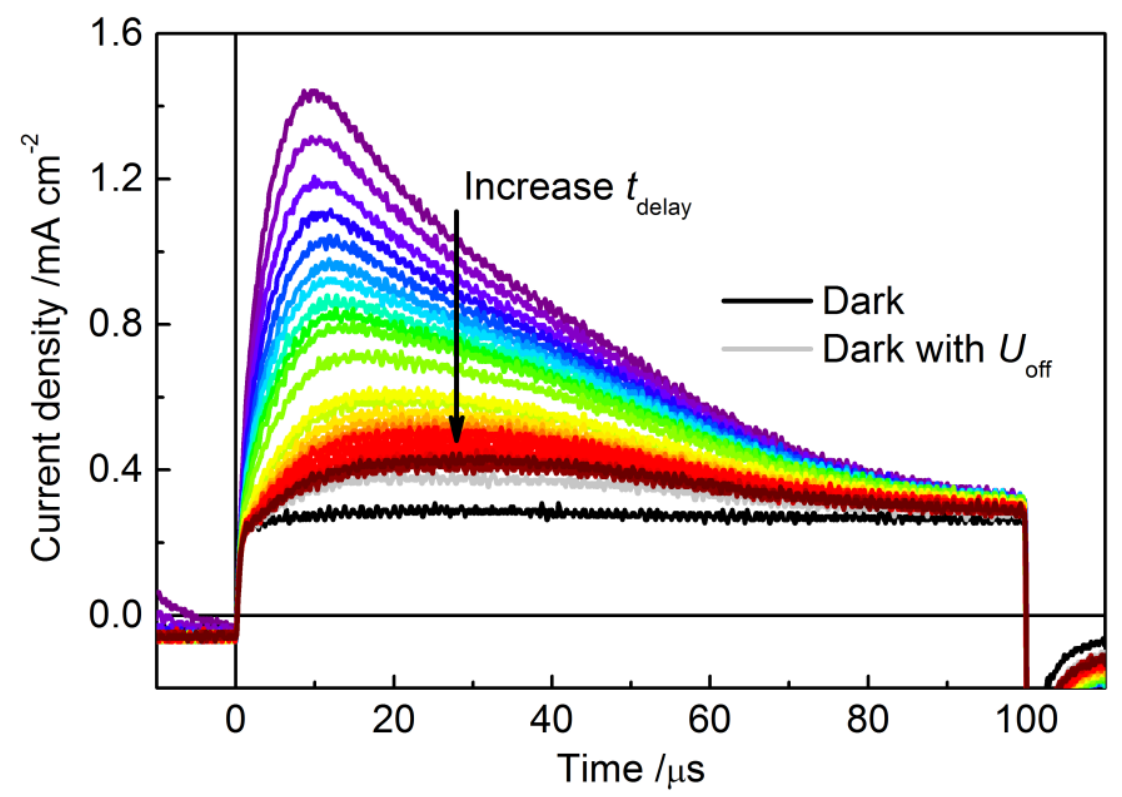

Figure S3. Photo-CELIV transients of a solar cell with an active layer thickness of $d=450 \mathrm{~nm}$. 


\section{Device parameters}

Solar cells were characterized with a Keithley 2400 meter under simulated AM 1.5 solar illumination $\left(100 \mathrm{~mW} / \mathrm{cm}^{2}\right)$, calibrated with a silicon reference solar cell (SRC-1000-RTD).

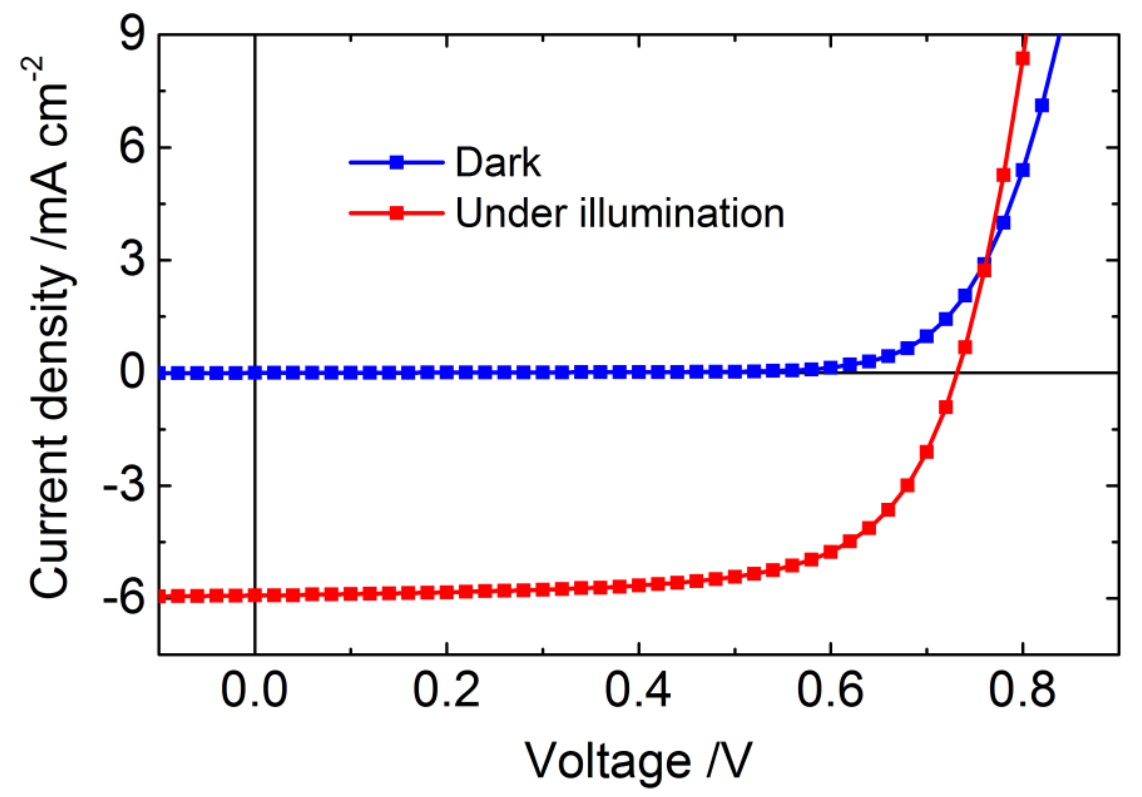

Figure S4. $J-V$ characteristic curves of TQ1:PC ${ }_{71} \mathrm{BM}$ semitransparent solar cells in the dark and under simulated AM 1.5 illumination. $J_{\mathrm{sc}}=5.92 \mathrm{~mA} / \mathrm{cm}^{2}, V_{\mathrm{oc}}=0.73 \mathrm{~V}$, $F F=0.66, P C E=2.88 \%$.

\section{References}

[1] W. J. Grzegorczyk, T. J. Savenije, T. E. Dykstra, J. Piris, J. M. Schins, L. D. A. Siebbeles, J. Phys. Chem. C 2010, 114, 5182-5186.

[2] D. H. K. Murthy, M. Gao, M. J. W. Vermeulen, L. D. A. Siebbeles, T. J. Savenije, J. Phys. Chem. C 2012, 116, 9214-9220.

[3] M. P. de Haas, J. M. Warman, T. D. Anthopoulos, D. M. de Leeuw, $A d v$. Funct. Mater. 2006, 16, 2274-2280.

[4] N. Nekrašas, K. Genevičius, M. Viliūnas, G. Juška, Chemical Physics 2012, 404, 56-59. 